\title{
Left ventricular aneurysm as a rare complication of an acute myocardial infarction: a case report
}

\section{- Saška Bojanić*, -Biljana Hržić}

Klinička bolnica Dubrava, Zagreb, Hrvatska

University Hospital Dubrava, Zagreb, Croatia
RECEIVED:

September 7, 2021

ACCEPTED:

September 14, 2021

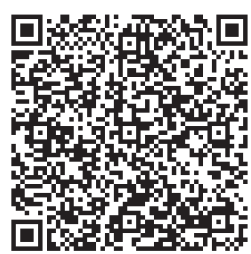

KEYWORDS: left ventricular aneurysm, COVID-19, nursing care.

CITATION: Cardiol Croat. 2021;16(11-12):367. | https://doi.org/10.15836/ccar2021.367

*ADDRESS FOR CORRESPONDENCE: Saška Bojanić, Klinička bolnica Dubrava, Avenija Gojka Šuška 6, HR-10000 Zagreb, Croatia. / Phone +385-1-290-2545 / E-mail: saskabojanic@gmail.com

ORCID: Saška Bojanić, https://orcid.org/0000-0003-0551-5313 • Biljana Hržić, https://orcid.org/0000-0001-5441-0900

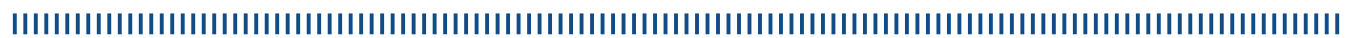

Introduction: A left ventricular aneurysm is an outburst of the heart wall and is one of the late complications of myocardial infarction. The main factors for the development of an aneurysm are complete anterior incoming artery occlusion and failure to achieve coronary artery permeability at the area of infarction. ${ }^{1}$

Case report: We present a 55-year-old female patient whose symptoms of pneumonia due to COVID-19 infection had "masked" the clinical state of acute myocardial infarction. The treatment was initiated in Primary respiratory - intensivist center in University Hospital Dubrava. She was a patient with longstanding hypertension and diabetes. Based on medical history and examination, ECG, coronary angiography, and dynamics of cardioselective enzymes, subacute myocardial infarction was diagnosed, and the patient was treated conservatively. After discharge from the hospital, the patient underwent echocardiography showing the formation of a postinfarction aneurysm at the left ventricle with thrombus formation. The patient was further monitored through a cardiac daily hospital unit for titration of anticoagulant therapy with warfarin. At the last follow-up, the significant progression of the left ventricular aneurysm was verified by echocardiography. The patient was urgently admitted to the Coronary Care Unit where detailed diagnostics was performed, including MSCT of the heart according to the TAVI protocol and cardiac MRI natively and in the delayed phase. The findings showed progression and growth of the pseudoaneurysm to the pre-existing aneurysm extension in the left ventricle. This case report provides an overview of nursing care expectations at the intensive cardiac care unit with a focus on teamwork, professional communication, and patient preparation for diagnostic procedures. Furthermore, it is important to emphasize that the demands for medical care during pandemics are not common and show a constant lack of highly trained cardiologists and cardiac nurses.

LITERATURE IIIIIIIIIIIIIIIIIIIIIIIIIIIIIIIIIIIIIIIIIIIIIIIIIIIIIIIIIIIIIIIIIIIIIIIIIIIIIIIIIIIIIIIIIIIIIIIIII

1. Antunes MJ, Antunes PE. Left-ventricular aneurysms: from disease to repair. Expert Rev Cardiovasc Ther. 2005 Mar;3(2):285-94. https://doi.org/10.1586/14779072.3.2.285
Cardiologia Croatica $\square$ 2021:16(11-12):367. 